Article

\title{
PER, a Circadian Clock Component, Mediates the Suppression of MMP-1 Expression in HaCaT Keratinocytes by cAMP
}

\author{
Miji Yeom, HansongI Lee, Seoungwoo Shin ${ }^{\mathbb{D}}$, Deokhoon Park and Eunsun Jung * \\ Biospectrum Life Science Institute, A-1805, U-TOWER, 767, Sinsu-ro, Suji-gu 16827, Yongin-si, Gyeonggi-do, \\ Korea; biout@biospectrum.com (M.Y.); bioyw@biospectrum.com (H.L.); biost@biospectrum.com (S.S.); \\ pdh@biospectrum.com (D.P.) \\ * Correspondence: bioso@biospectrum.com; Tel.: +82-705-117-0029
}

Received: 14 February 2018; Accepted: 19 March 2018; Published: 23 March 2018

\begin{abstract}
Skin circadian clock system responds to daily changes, thereby regulating skin functions. Exposure of the skin to UV irradiation induces the expression of matrix metalloproteinase-1 (MMP-1) and causes DNA damage. It has been reported both DNA repair and DNA replication are regulated by the circadian clock in mouse skin. However, the molecular link between circadian clock and MMP-1 has little been investigated. We found PERIOD protein, a morning clock component, represses the expression of MMP-1 in human keratinocytes by using a PER-knockdown strategy. Treatment with siPer3 alleviated the suppression of MMP-1 expression induced by forskolin. Results revealed PER3 suppresses the expression of MMP-1 via cAMP signaling pathway. Additionally, we screened for an activator of PER that could repress the expression of MMP-1 using HaCaT cell line containing PER promoter-luciferase reporter gene. Results showed Lespedeza capitate extract (LCE) increased PER promoter activity. LCE inhibited the expression of MMP-1 and its effect of LCE was abolished in knockdown of PER2 or PER3, demonstrating LCE can repress the expression of MMP-1 through PER. Since circadian clock component PER can regulate MMP-1 expression, it might be a new molecular mechanism to develop therapeutics to alleviate skin aging and skin cancer.
\end{abstract}

Keywords: skin circadian clock; PER; MMP-1; cAMP; Lespedeza capitata

\section{Introduction}

The circadian clock is an endogenous timing mechanism that allows anticipation of regular daily changes and operation of biological processes at proper time during a day. Studies in mice have shown that a disruption of internal rhythms causes premature aging and reduces life span and fertility rates, thereby having negative consequences for fitness [1,2]. In mammals, the central clock is in the suprachiasmatic nucleus (SCN) of the hypothalamus, which receives environmental timing

Information through the retina. It is essential for synchronization of organisms with periodic environmental changes [3,4]. Most peripheral tissues have self-sustaining oscillators synchronized by the central clock via systemic time cues such as hormonal and neuronal signals $[5,6]$. Peripheral clocks regulate local physiology in a circadian manner [7]. At a molecular level, the circadian clock consists of interlocked transcription-translation feedback loop of PER 1-3 (Period 1-3) and Cry 1-2 (Crytochromes 1 and 2) genes. Expression of these genes is activated by transcription factors BMAL1 (brain and muscle aryl hydrocarbon receptor nuclear translocator (ARNT)-like protein-1) and CLOCK (circadian locomotor output cycles kaput) [8].

Since skin is positioned at the interface between body and environment, it is subjected to daily variations in environments such as light, temperature, UV radiation, humidity, and pathogens. 
Many human skin properties oscillate in a circadian manner including cell proliferation rates, hydration and transepidermal water loss (TEWL), sebum production, surface $\mathrm{pH}$, temperature, and facial rhytides [9-14]. It has been reported that clock genes BMAL1, CLOCK, PER, and CRY are expressed in cultured human skin cells including keratinocytes, melanocytes, and dermal fibroblasts [15]. Each of these diverse skin cell types contains distinct circadian clock machinery that autonomously drives daily functions. At molecular level, core clock component can regulate approximately $2-10 \%$ of total genome in each tissue including skin [16,17]. Disruption of core circadian clock genes affects the gene expression and cellular processes important for skin function.

Acute and chronic exposure of the skin to UV irradiation induces MMP-1 expression and causes DNA damage, ultimately leading to premature skin aging (photoaging) and skin cancer $[18,19]$. It has been reported that both DNA repair, which is a mechanism for removing UV photoproducts, and DNA replication are regulated by the circadian clock in mouse skin. Oscillation of xeroderma pigmentosum complementation group A (XPA), one of six core factors important for removing UV photoproducts from DNA, has the lowest level during the night, in parallel with oscillation of repair activity [20-22]. It has been reported that the highest proportion of epidermal progenitor/stem cell proliferation in mice is in S-phase during the night [9].

MMPs is composed of a family of zinc-containing proteinases that are responsible for degradation of extracellular matrix (ECM) proteins such as collagen, fibronectin, elastin, and proteoglycans, contributing to photoaging [23-25]. The major enzyme responsible for collagen 1 digestion, MMP-1, is induced by exposure to sunlight [26]. UVB-irradiated keratinocytes stimulate MMP-1 release from fibroblasts. Also, damaged keratinocytes activate MMP-1 release by self. MMP-1 secreted from keratinocytes and fibroblasts impair the structural integrity of the dermis and result in the re-modelling of the skin $[27,28]$. MMP-1 expression is regulated by diverse signaling pathways. Of those pathways, cAMP signaling can inhibit MMP-1 expression in human skin fibroblasts [29]. cAMP signaling pathways also has been involved in circadian clock entraining and light-induced clock resetting [30]. Activated PKA by cAMP stimulates cAMP-response element binding protein (CREB) which induces cellular genes containing cAMP-response element (CRE) including PER. Light activation of PER genes is achieved through CREB/CRE signaling [31-33]. Although there are clues about the relation between MMP-1 and circadian clock, a direct molecular link between the circadian clock and MMP-1 has little been investigated.

To understand the molecular link between the circadian clock and MMP-1, we examined the effect of circadian clock on MMP-1 expression in human adult low calcium temperature (HaCaT) keratinocytes after knocking down core clock genes. We found that knockdown of PER increased the expression of MMP-1 regulated by cAMP signaling. Furthermore, we found that Lespedeza capitata extract could inhibit the expression of MMP-1 by activating the expression of PER gene. Our results suggest that the circadian clock protein PER might play a key role in regulating MMP-1 expression.

\section{Results}

\subsection{Knockdown of PER Proteins Increase the Expression of MMP-1 in HaCaT Cells}

To study the potential impact of the circadian clock on MMP-1, we investigated whether core clock protein, BMAL1, PER1, PER2, and PER3 could directly regulate the expression of MMP-1. HaCaT cells were transfected with each of BMAL1-, PER1-, PER2-, and PER3-siRNA. At $72 \mathrm{~h}$ after transfection, total RNA was extracted from transfected cells. Endogenous levels of BMAL1, PER1, PER2, and PER3 were effectively knocked down by their respective siRNA (about 60\% knockdown by BMAL1-, PER1-, and PER3-siRNA and about 50\% knockdown by PER2-siRNA compared to a scrambled nontargeting siRNA) based on quantitative real-time PCR results (Figure 1A). Cells transfected with each of BMAL1-, PER1-, PER2-, and PER3-siRNA were used to measure transcriptional levels of MMP-1. Knockdown of PER2 and PER3 increased transcriptional levels of MMP-1 as much as two or three times while knockdown of BMAL1 slightly increased transcriptional levels of MMP-1 compared to non-knockdown 
control treated with control-siRNA. However, knockdown of PER1 decreased transcriptional levels of $M M P-1$ by about half compared to control-siRNA treatment (Figure 1B). Secreted MMP-1 protein levels were determined by ELISA. The results revealed that treatment with BMAL1-, PER2-, and PER3-siRNA increased secreted MMP-1 protein levels (Figure 1C), similar to results obtained by real-time PCR. Among different treatments, knockdown of PER3 showed the strongest effect on the expression of $M M P-1$. These results revealed that core clock proteins could directly regulate the expression of MMP-1. Especially, PER2 and PER3, as components of morning clock could function as inhibitors of $M M P-1$ expression.

(A)

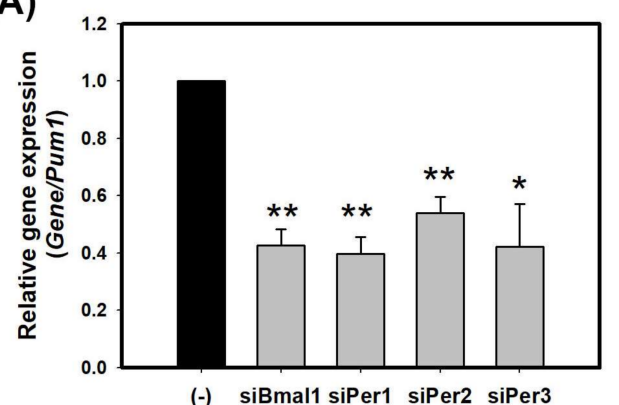

(C)

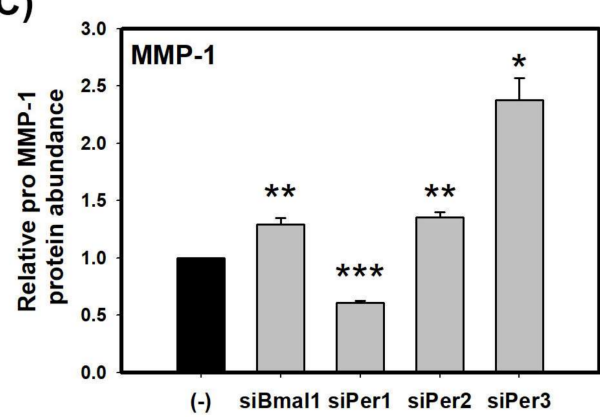

(B)

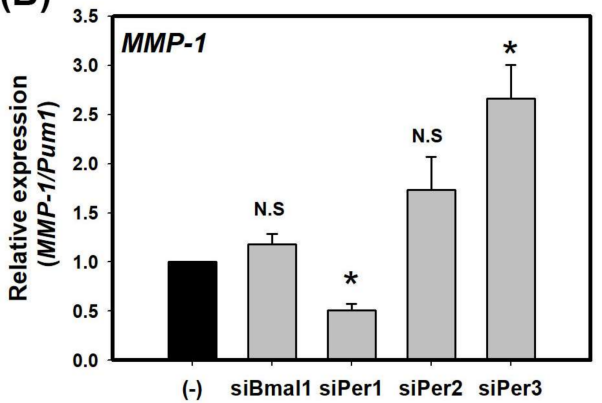

Figure 1. Core clock proteins regulate the expression of MMP-1 in HaCaT cells. (A) Transcriptional levels of endogenous clock genes in HaCaT cells transfected with control-siRNA, siBmal1, siPer1, siPer2, and siPer3 for $72 \mathrm{~h}$; (B) Levels of MMP-1 transcripts in HaCaT cells transfected with control-siRNA, siBmal1, siPer1, siPer2, and siPer3 for $72 \mathrm{~h}$; (C) Levels of pro MMP-1 proteins in cell supernatants of HaCaT cells transfected with control-siRNA, siBmal1, siPer1, siPer2, and siPer3 for $72 \mathrm{~h}$. Data are presented as mean \pm SEM from three replicated measurements. Data is the relative value compared with control group. (Two-tail unpaired $t$-test, $n=3,{ }^{*} p<0.05,{ }^{* *} p<0.01$, ${ }^{* *} p<0.001$ compared with control-siRNA, N.S.: not significant).

\subsection{Suppression of MMP-1 by cAMP is Mediated by PER}

Expression of MMP-1 can be activated by diverse external and internal stimuli such as UV radiation, toxic exposure, oxidative stress, and aging. It is likely to be regulated by many signaling pathways. Of those pathways, cAMP signaling can inhibit MMP-1 expression in human skin fibroblasts [29]. cAMP-dependent signaling plays an important role in sustaining circadian oscillation through cAMP-response element (CRE) [31-33]. Here, we investigated the involvement of cAMP signaling in the inhibitory effect of PER on expression of MMP-1 in keratinocytes. To examine whether an increase of cAMP could influence the expression of $M M P-1, \mathrm{HaCaT}$ cells were treated with forskolin (FSK), a cAMP-inducing agent, at indicated concentrations. FSK suppressed transcriptional levels of $M M P-1$ in a dose-dependent manner. After treatment with $10 \mu \mathrm{M}$ FSK, transcriptional levels of $M M P-1$ was significantly decreased (by about 80\%) (Figure 2A). It has been reported that many biological processes of cAMP signaling are mediated through PKA pathway [34-36]. To examine whether PKA pathway is involved in the suppression of $M M P-1$ by cAMP, we treated HaCaT cells with both $\mathrm{H}-89$ 
(a specific a PKA inhibitor, $10 \mu \mathrm{M}$ ) and FSK. Transcriptional level of $M M P-1$ from cells co-treated with H-89 and FSK was increased about three times when compared to that from cells treated with FSK only (Figure 2A). These results showed that H-89 could antagonize the suppression of $M M P-1$ expression by cAMP, indicating that PKA activity might mediate the effect of cAMP on $M M P-1$ expression.

(A)

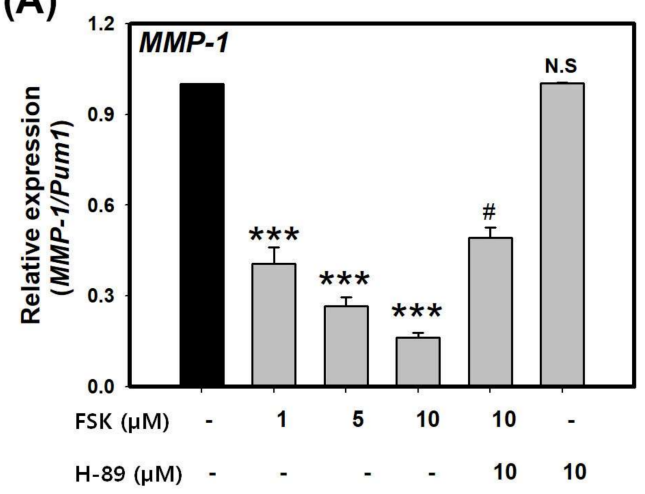

(C)

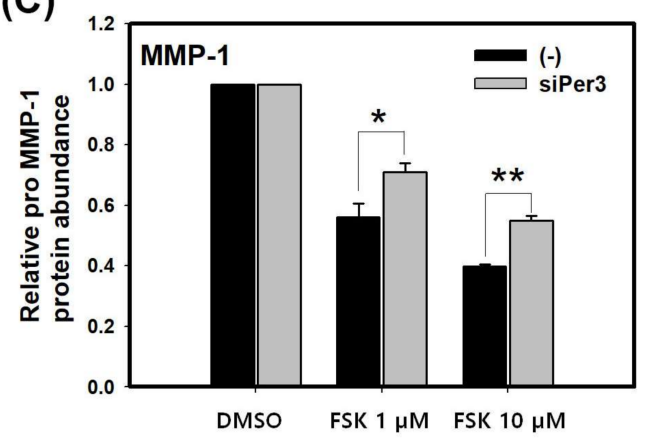

(E)

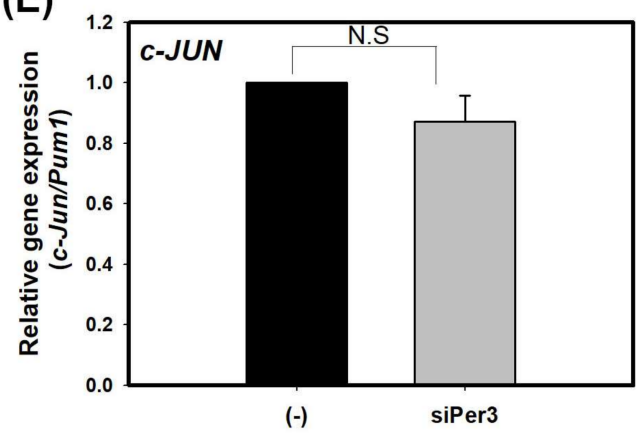

(B)

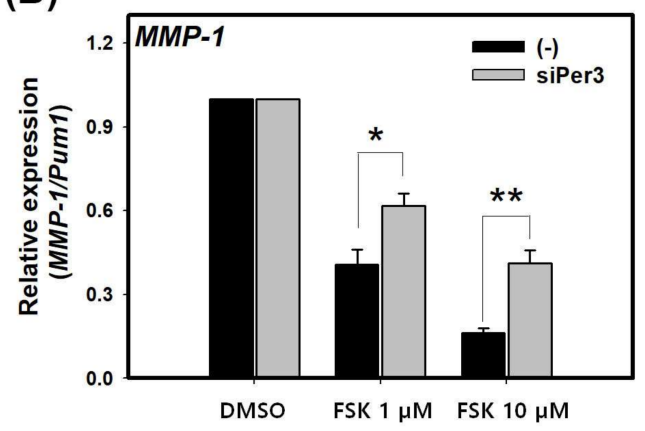

(D)

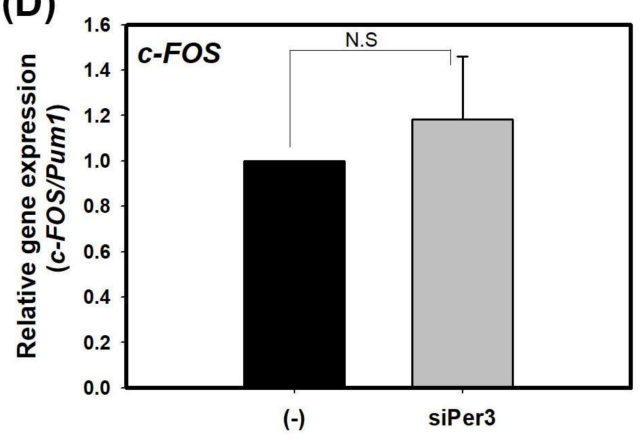

Figure 2. cAMP suppresses the expression of MMP-1 through PER3 in HaCaT cells. (A) Levels of MMP-1 transcripts in HaCaT cells treated with DMSO (-), FSK, and H-89 at indicated concentration for $24 \mathrm{~h}$ (two-tail unpaired, $n=3,{ }^{*} p<0.05,{ }^{* *} p<0.01,{ }^{* * *} p<0.001$, N.S.: not significant compared with DMSO only (-) and ${ }^{*} p<0.05$ compared with 10 uM FSK); (B) Levels of MMP-1 transcripts in HaCaT cells treated with control-siRNA or siPer3 for $48 \mathrm{~h}$, followed by co-treatment with FSK and siRNA for $24 \mathrm{~h}$; (C) Levels of pro MMP-1 proteins in cell supernatants of HaCaT treated with control-siRNA or siPer3 for $48 \mathrm{~h}$, followed by co-treatment with FSK and siRNA for $24 \mathrm{~h}$ (in B,C, one-way ANOVA, followed by Bonferroni post hoc, $n=3$, ${ }^{*} p<0.05$, ${ }^{* *} p<0.01$ compared with control-siRNA at the indicated concentration) levels of c-Fos (D) and c-Jun (E) transcripts in aCaT cells treated with control-siRNA or siPer3 for $72 \mathrm{~h}$ (Two-tail unpaired, $n=3$, N.S.: not significant compared with control-siRNA). Data are presented as mean \pm SEM from three replicated measurements. Data is the relative value compared with control group in $(\mathbf{A}, \mathbf{D}, \mathbf{E})$ or compared with respective control group (control-siRNA or siPer3 at DMSO) in (B,C). 
To determine whether PER could suppress the expression of MMP-1 through cAMP signaling, we tested the effect of FSK on MMP-1 expression after knockdown of PER3 because siPer3 showed the strongest effect on the expression of MMP-1. We tested the effect of PER3 on expression of MMP-1 through cAMP signaling. In the control-siRNA group, the transcriptional levels of MMP-1 was significantly decreased by treatment with FSK in a dose-dependent manner. However, in the siPer3 treatment group, the inhibitory effect of FSK on MMP-1 mRNA was significantly attenuated compared to that in the control siRNA group (Figure 2B). With respect to the secreted MMP-1 protein levels, cells transfected with control siRNA showed significant decrease compared to cells transfected with siPer3 (Figure 2C), similar to real-time PCR results at mRNA level. These results suggest that cAMP signaling contributes to the suppression of MMP-1 and this signaling is partially mediated by clock protein PER3.

A previous report has shown that cAMP signaling represses MMP-1 expression through PKA-mediated inhibition of extracellular signal-regulated kinase (ERK) and c-Jun N-terminal kinase (JNK) that can sequentially activate AP-1 complex composing of c-FOS and c-JUN [29]. AP-1 complex is a major transcription factor of $M M P-1$ gene. Therefore, we hypothesized that the repression of MMP-1 by PER3 might be under CAMP-mediated ERK and JNK signaling. To test this hypothesis, we examined expression levels of $c-F O S$ and $c-J U N$ after knockdown of PER3. Results showed that knockdown of PER3 did not influence the expression of c-FOS or c-JUN (Figure 2D,E), this suggests that PER3-mediated suppression of MMP-1 by cAMP is independent of ERK/JNK signaling.

\subsection{LCE Increases PER Activity in HaCaT Cells}

Our results obtained above suggest that skin circadian clock might be a new mechanism for regulating MMP-1. To confirm the role of circadian clock on regulating MMP-1 expression, we first searched for a modulator of circadian rhythm. To monitor skin circadian rhythm, we measured activities of $B M A L 1$ and $P E R 2$ genes. It has been reported that $P E R 2$ gene oscillates with high amplitude rather than PER3 gene in fibroblasts and keratinocytes [15]. We generated Per2pro-LUC/Bmal1pro-LUC cell line containing firefly luciferase gene (LUC) under the control of a 526bp PER2 promoter fragment from mouse genome or a 1.34-Kb BMAL1 promoter fragment from human genome. These reporter constructs were stably integrated into $\mathrm{HaCaT}$ keratinocytes and single reporter clones were obtained. It has been reported that $P E R 2$ promoter regions show high homology between mice and humans [37]. Circadian rhythms were synchronized with $1 \mu \mathrm{M}$ dexamethasone for one hour and rhythmic luciferase activity of live cells was monitored for five days with a real-time monitoring system. Results showed that PER2 or BMAL1 promoter activity oscillated persistently for five days (Figure 3A). Reporter clones of PER2 promoter activity with a period of $25.48 \pm 0.17 \mathrm{~h}$, a RAE of $0.12 \pm 0.00$, and a phase of $7.25 \pm 0.25$ was obtained. Those of BMAL1 promoter activity with a period of $25.36 \pm 0.07 \mathrm{~h}$, a RAE of $0.13 \pm 0.01$, and a phase of $16.50 \pm 0.29(\mathrm{SEM}, n=3$ ) were obtained (Table 1). Each rhythm expressed in an anti-phasic manner. These results revealed that skin circadian rhythm could be measured at cellular level in HaCaT cells using Per2pro-LUC/Bmal1pro-LUC cell line. We then searched for an activator of PER2 activity using Per2pro-LUC reporter cell line and various plant extracts. We found several putative activators of PER. Among those, L. capitata extract (LCE) showed significant activation of Per2pro-LUC in a dose-dependent manner. After treatment with $50 \mu \mathrm{g} / \mathrm{mL}$ LCE, PER2 activity was increased by $47 \%$ at $30 \mathrm{~h}$ after treatment compared with to that in untreated sample at $28 \mathrm{~h}$ after treatment (Figure 3B). LCE slightly lengthened the period of PER2 promoter activity without changing RAE (Figure 3C, Table 1). These results showed PER2 promoter activity of the control group had a period of $24.87 \pm 0.02 \mathrm{~h}$ and a RAE of $0.16 \pm 0.00$ (SEM, $n=3$ ) while that of the experimental group treated with $50 \mu \mathrm{g} / \mathrm{mL} \mathrm{LCE} \mathrm{had} \mathrm{a} \mathrm{period} \mathrm{of} 25.18 \pm 0.00 \mathrm{~h}$ and a RAE of $0.17 \pm 0.00(\mathrm{SEM}, n=3$ ) (Table 1). Next, we determined whether the increase of PER2 activity was caused by an increase in the number of cells or an increase of PER2 activity in single cells. The number of cells incubated with LCE at $30 \mathrm{~h}$ after treatment when PER2 expression was the highest was counted. The number of cells treated 
with LCE was not changed compared to that of untreated cells (Figure 3D). These results showed that LCE extract could increase PER2 activity without affecting cell proliferation or cytotoxicity.

(A)

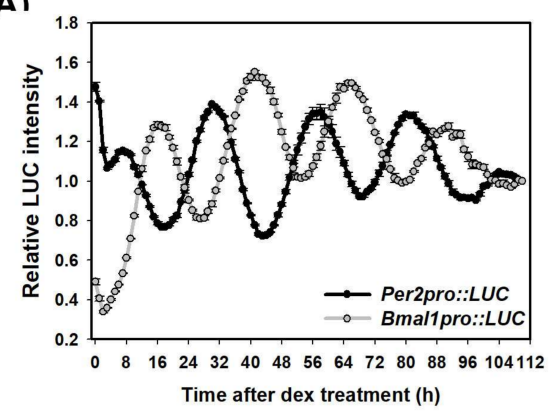

(C)

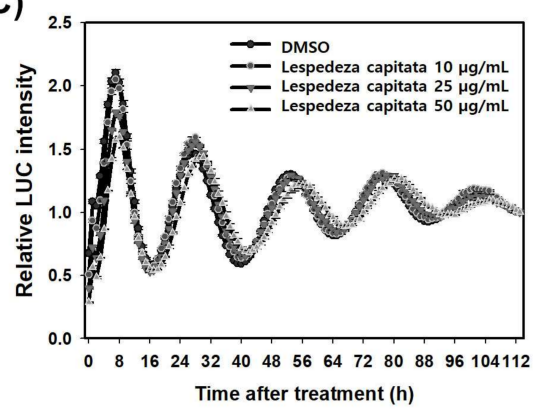

(B)

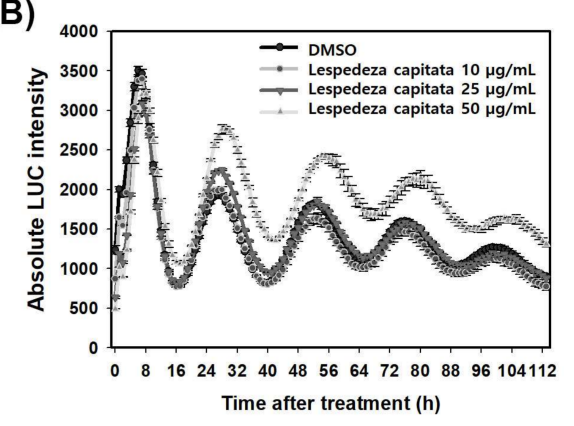

(D)

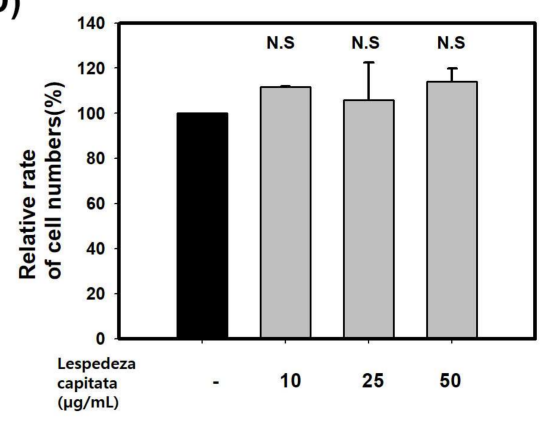

Figure 3. LCE increases PER promoter activity in HaCaT cells. (A) Per2pro::LUC and Bmal1pro::LUC reporter cell line. Circadian rhythms of single reporter cell clones were treated with $1 \mu \mathrm{M}$ dexamethasone for 1 hour and bioluminescence was recorded for five days. Data were the de-trended time series of a representative single reporter cell clone. (B) Absolute bioluminescence of Per2pro::LUC treated with LCE for $24 \mathrm{~h}$; (C) Relative bioluminescence of Per2pro::LUC treated with LCE for $24 \mathrm{~h}$; (D) Relative rate of numbers in cells treated with LCE at $30 \mathrm{~h}$ after treatment was shown. Cells were counted using a cell counter. Data are presented as mean \pm SEM from three replicated measurements (two-tail unpaired, $n=3$, N.S.: not significant compared with DMSO (-)).

Table 1. Analysis of circadian rhythm. Relative luminescence intensities from each data in Figure 3A, C imported into the Biological Rhythms Analysis Software System (BRASS), and periods and relative amplitude error (RAE) were analyzed using the FFT-NLLS suite.

\begin{tabular}{|c|c|c|c|c|c|}
\hline & & Per2pro::LUC & & Bmal1pro::LU & \\
\hline \multirow{2}{*}{ Period (h) } & Average & 25.48 & \multicolumn{3}{|c|}{25.36} \\
\hline & S.E & 0.17 & \multicolumn{3}{|c|}{0.07} \\
\hline \multirow{2}{*}{ Amplitude } & Average & 0.24 & \multirow{2}{*}{\multicolumn{3}{|c|}{$\begin{array}{l}0.26 \\
0.00\end{array}$}} \\
\hline & S.E & 0.01 & & & \\
\hline \multirow[b]{2}{*}{ R.A.E } & Average & 0.12 & \multicolumn{3}{|c|}{0.13} \\
\hline & S.E & 0.00 & \multicolumn{3}{|c|}{0.01} \\
\hline \multirow{4}{*}{ Phase (h) } & Average & 7.25 & \multirow{2}{*}{\multicolumn{3}{|c|}{$\begin{array}{c}16.50 \\
0.29\end{array}$}} \\
\hline & S.E & 0.25 & & & \\
\hline & & \multirow{2}{*}{ DMSO } & \multicolumn{3}{|c|}{ Lespedeza Capitata } \\
\hline & & & $10 \mu \mathrm{g} / \mathrm{mL}$ & $25 \mu \mathrm{g} / \mathrm{mL}$ & $50 \mu \mathrm{g} / \mathrm{mL}$ \\
\hline \multirow{2}{*}{ Period (h) } & Average & 24.87 & 24.72 & 25.01 & 25.53 \\
\hline & S.E & 0.02 & 0.03 & 0.01 & 0.04 \\
\hline \multirow{2}{*}{ Amplitude } & Average & 0.29 & 0.28 & 0.27 & 0.22 \\
\hline & S.E & 0.00 & 0.00 & 0.00 & 0.00 \\
\hline \multirow{2}{*}{ R.A.E. } & Average & 0.16 & 0.17 & 0.17 & 0.19 \\
\hline & S.E & 0.00 & 0.00 & 0.00 & 0.00 \\
\hline \multirow{2}{*}{ Phase (h) } & Average & 7 & 7 & 7 & 8 \\
\hline & S.E & 0 & 0 & 0 & 0 \\
\hline
\end{tabular}




\subsection{LCE Suppresses the Expression of MMP-1 through PER in HaCaT Cell}

To determine LCE, PER activator, exerts inhibitory effect on expression of MMP-1, we measured expression levels of MMP-1 in LCE treated group using real-time PCR and ELISA. LCE significantly decreased MMP-1 at mRNA and secreted protein levels in a dose-dependent manner (Figure 4A-D). We then determined whether the inhibition of MMP-1 expression by LCE was mediated by PER. HaCaT cells were transfected with siPER2 and siPER3 for $48 \mathrm{~h}$ followed by treatment with LCE for 24 h. Silencing of PER2 or PER3 by siRNA partially alleviated the effect of LCE on the suppression of $M M P-1$ at mRNA and secreted protein levels compared to treatment by control siRNA (Figure 4A-D). Taken together, these results indicate that LCE can suppress $M M P-1$ expression through circadian clock gene PER. Therefore, activator of circadian clock might be a new mechanism to regulate MMP-1.
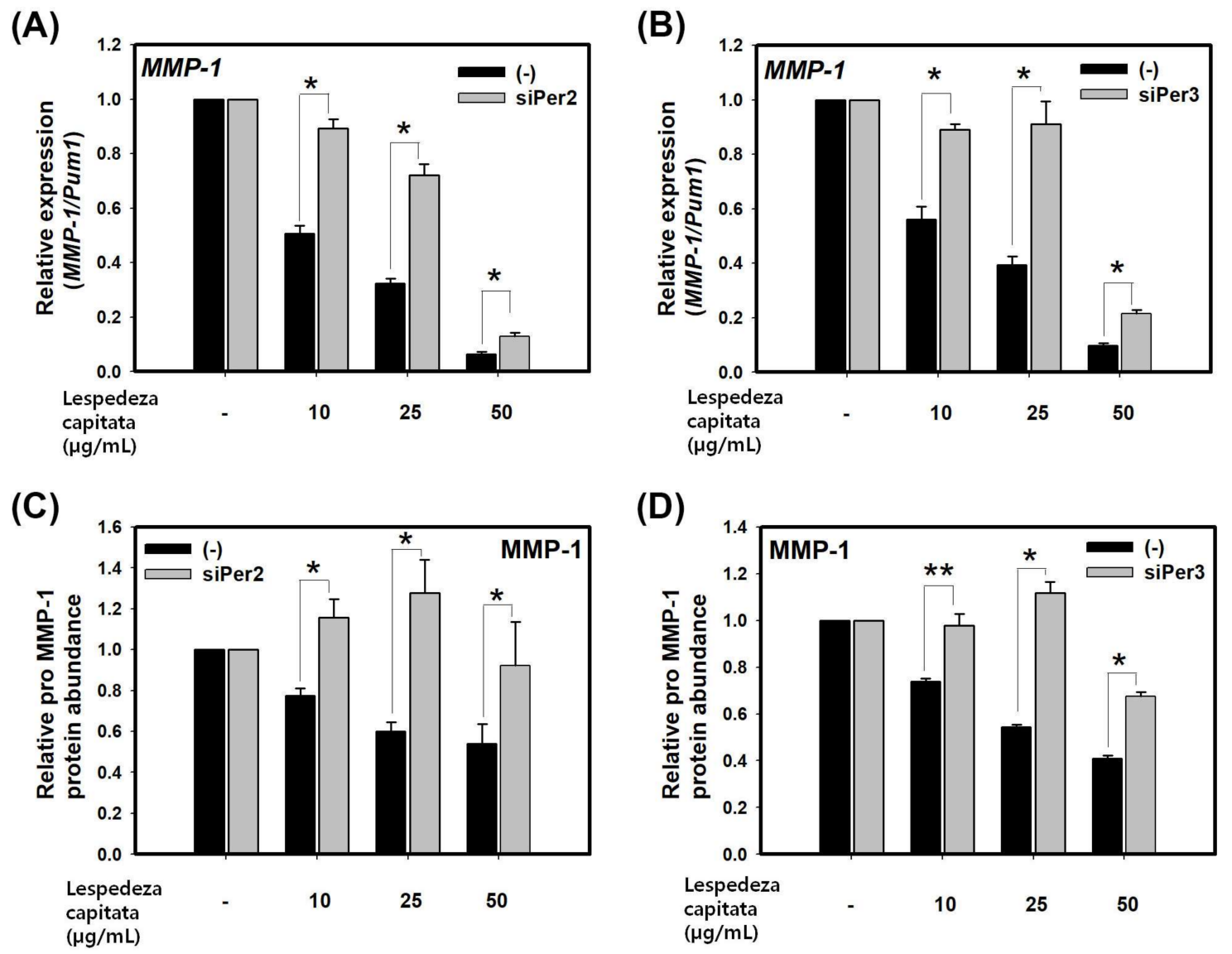

Figure 4. LCE suppresses the expression of MMP-1 through PER in HaCaT cells. Levels of MMP-1 transcripts (A) and pro MMP-1 protein (C) in HaCaT cells treated with control-siRNA and siPer2 for 48 $\mathrm{h}$ followed by treatment with LCE for $24 \mathrm{~h}$. Levels of MMP-1 transcripts (B) and pro MMP-1 protein (D) in HaCaT cells treated with control-siRNA and siPer3 for $48 \mathrm{~h}$ followed by treatment with LCE for $24 \mathrm{~h}$. Data are presented as mean \pm SEM from three replicate measurements. Data is the relative value compared with respective control group (control-siRNA or siPer3 at DMSO) (one-way ANOVA, followed by Dunnett T3 post hoc, $n=3,{ }^{*} p<0.05,{ }^{* *} p<0.01$ compared with control-siRNA at indicated concentration).

\section{Discussion}

The circadian clock imparts 24-h rhythmicity on gene expression and cellular physiology in the cell. It has been reported that disruption of circadian clock genes can lead to diverse defects on gene expression important for skin function. Bmal1-deficient mutant mice have shown upregulated ROS levels and reduced lifespans and various symptoms of premature aging, suggesting that it might play a 
role in aging by regulating genes involved in anti-oxidant process [38]. In human keratinocytes, CLOCK regulates the expression of Aquaporin (AQO)-3 and tissue inhibitor of metalloproteinase (TIMP)-3 that control hydration and photoaging, respectively [39,40]. Knockdown of PER has shown diverse defects in cell differentiation, wound healing, autophagy in aging, and tumor development [15,41-44]. In epidermal stem cells, increase in PER1 and PER2 confers a more deterministic propensity toward differentiation due to increased expression of differentiation markers IVL and loricrin [17]. In fibroblasts, PER protein can bind to RNA binding protein NONO and activate p160-Ink4A cell cycle check-point gene in circadian-dependent manner. Due to the role of PER on the cell cycle, loss of PER has shown defects in the wound healing process by reducing epidermal regeneration, dermal organization, and collagen deposition [41]. It is well-known that MMP also plays a role in would healing by degrading collagen and other ECM proteins comprising connective tissues. Our data showed that knockdown of PER increased MMP-1 expression. We hypothesize that changes in dermal organization and collagen deposition not only could be caused by activation of p160-Ink4A, but also by inhibition of MMP-1 by PER protein. In tumor development, PER1 suppresses expression levels of tumor-related genes including $c-M Y C$ gene [43]. Especially, activation of RAS/MAPK signaling increases the expression of MMP-1 but represses PER expression in tumor cell lines [45]. This is consistent with the fact that PER3 protein is a tumor suppressor gene [46]. These reports suggest that repression of MMP-1 by PER might be one mechanism involved in tumor development. Taken together, these results demonstrate that disruption of core clock genes affects gene expression and cellular processes. Therefore, reinforcing the level of core clock genes is necessary to sustain biological fitness.

The skin peripheral clock can be disrupted by external and internal signals such as UV radiation, pathogen, and aging [46-48]. Synthetic drug-like molecules and plant extracts that directly modulate the activity of key clock proteins might have potential to directly regulate clock-controlled genes important for skin function [49-52]. For pharmacological targeting of the skin circadian clock, many studies have established a viable model system using luciferase-based reporter system containing BAML1 or PER2 promoter fragment. In HaCaT keratinocytes, the circadian clock robustly oscillates in individual cells [53]. Therefore, we used this reporter system in HaCaT keratinocytes to study circadian rhythm in epidermal keratinocytes and screened for a modulator of circadian rhythm. The period, amplitude, phase, and level of circadian rhythm can be affected by certain molecules in a variety of manners. Such effects can be dependent on chronic or transient exposure to the molecule.

Our data showed that forskolin repressed the expression of MMP-1 while knockdown of PER3 partially restored its effect. A previous report has shown that cAMP signaling can repress MMP-1 expression through inhibiting ERK, JNK, and sequential AP-1 complex composed of c-FOS and c-JUN [29]. However, our results showed that knockdown of PER3 did not influence the expression of $c$-FOS or $c$-JUN. This means that another mechanism might be responsible for cAMP-mediated repression of MMP-1. It has been reported that activated PKA by cAMP can lead to activation of PER gene through CREB/CRE signaling [31-33]. Taken together, these results suggest that cAMP can repress the expression of MMP-1 not only through PKA-mediated inhibition of AP-1 complex, but also through PKA-mediated activation of PER.

The circadian clock is an endogenous timing mechanism that allows the anticipation of regular daily changes and the operation of biological processes at proper time in a day, thereby increasing fitness. In human epidermal stem cells, the intricate mechanism of the circadian clock keeps homeostasis by offering epidermal stem cells with environmental cues. During the day time, human keratinocytes induce DNA replication, protection to UV, and, subsequently, cell division. They offer protection against UV when they tend to duplicate their DNAs (more sensitive to UV-induced DNA damage). Our data showed that a morning component PER gene repressed the expression of MMP-1. PER gene peaks between late-night and morning transition. At $5 \mathrm{~h}$ after PER3, the genes involved in proliferation and protection against UV subsequently sequentially peak in human keratinocytes [17]. Thus, repression of MMP-1 by PER might be one of protection mechanisms against UV. Disruption of skin circadian clock by UV radiation and aging might contribute to skin aging and skin cancer. 
This is consistent with previous reports showing that PER protein plays a role in skin aging and skin cancer $[42,43,45]$.

Our study is the first demonstration that Bmal1, Per1, Per2, and Per3 knockdown in HaCaT cells regulates expression of MMP-1. Especially, Per3 knockdown considerably upregulates MMP-1 expression. Also, the repression of MMP-1 by PER3 is mediated through cAMP signaling. It has been reported that MMP-1 is regulated by diverse signaling pathway such as MAPK signaling. We suggest the circadian clock can be a new mechanism for regulating MMP-1 expression in HaCaT cells. Based on our new findings, we anticipate investigating a role of PER gene in skin aging and skin cancer in vivo.

\section{Materials and Methods}

\subsection{Small-Interfering RNA Experiments and Pharmacological Treatment}

All siRNAs targeting the sequence of BMAL1, PER1, PER2, and PER3 were purchased from Santacruz Biotechnology (sc-38165, sc-38171, sc-36209, sc-38173, Dallas, TX, USA). To detect off-target effects, a non-targeting 20-25 nt siRNA (sc-37007) was used as a negative control siRNA. For transfection, HaCaT cells were seeded to white 12-well cell culture plates at density of $1.1 \times 105$ cells/well. After $24 \mathrm{~h}$ of culture, cells were transfected with $12.5 \mathrm{nM}$ of siRNA using Lipofectamine 2000 (Invitrogen, Carlsbad, CA, USA) and Opti-MEM (31985062, Gibco, Waltham, MA, USA) and according to manufacturers' instructions. At $72 \mathrm{~h}$ after transfection, cells were harvested to analyze mRNA expression.

For forskolin and $\mathrm{H}-89$ treatment, $\mathrm{HaCaT}$ cells were seeded to white 12-well cell culture plates at density of $1.1 \times 105$ cells / well. Cells were kept in DMEM containing $1 \%$ FBS. After $48 \mathrm{~h}$, cells were treated with 1 and $10 \mu \mathrm{M}$ FSK or $10 \mu \mathrm{M} \mathrm{H}-89$ purchased from Cell signaling technology (\#3828, \#9844, Danvers, MA, USA). After $24 \mathrm{~h}$ of treatment, cells were harvested for analyzing mRNA expression. For FSK and siRNA co-treatment, HaCaT cells were seeded to white 12 -well plates $(1.1 \times 105$ cells $/$ well $)$. After $24 \mathrm{~h}$, cells were transfected with $12.5 \mathrm{nM}$ of siRNA using Lipofectamine 2000 (Invitrogen, Carlsbad, CA, USA) and Opti-MEM according to manufacturer's instructions. At $48 \mathrm{~h}$ after transfection, cells were washed with PBS, treated with 1 or $10 \mu \mathrm{M}$ forskolin, and transfected with siPer3 or control siRNA for $24 \mathrm{~h}$. Cells were then harvested to analyze transcripts and protein levels.

For Lespedeza capitata extract (LCE) and siRNA treatment, HaCaT cells were seeded to white 12-well cell culture plates at density of $1.1 \times 105$ cells/well. After $24 \mathrm{~h}$ of incubation, cells were transfected with $12.5 \mathrm{nM}$ of siRNA using Lipofectamine 2000 (Invitrogen, Carlsbad, CA, USA) and Opti-MEM (31985062, Gibco, Waltham, MA, USA) according to manufactures' instructions. At $48 \mathrm{~h}$ after transfection, cells were washed with PBS and treated with LCE $(10,25$, and $50 \mu \mathrm{g} / \mathrm{mL})$ followed by transfection with siPer2/siPer3 or control siRNA for $24 \mathrm{~h}$. Cells were then harvested for analyzing transcripts and protein levels.

\subsection{RNA Isolation and Quantitative Real-Time RT-PCR}

We independently prepared samples for assays in triplicates. Total RNA was extracted using Qiagen RNeasy Mini Kit (Qiagen, Hilden, Germany) following the manufacturer's instructions. Complementary DNA was obtained by reverse transcription of $1 \mu \mathrm{g}$ of total mRNA using amfiRivert cDNA synthesis platinum master mix (GenDEPOT, Katy, TX, USA) following the manufacturer's instructions. Real-time reverse transcription PCR was done using an ABI PRISM 7300 (Applied Biosystems, Foster City, CA, USA). For a $20 \mu \mathrm{L}$ reaction, cDNA template was mixed with primers (final concentration of $300 \mathrm{nM}$ ) and $10 \mu \mathrm{L}$ of SYBR Green PCR Master Mix (4309155, Applied Biosystems, Foster City, CA, USA). PCR was performed with 40 cycles of $95{ }^{\circ} \mathrm{C}$ for $15 \mathrm{~s}, 55^{\circ} \mathrm{C}$ for $40 \mathrm{~s}$, and $72{ }^{\circ} \mathrm{C}$ for $30 \mathrm{~s}$ after an initial incubation at $95^{\circ} \mathrm{C}$ for $10 \mathrm{~min}$. Primer sequences are listed in Table 2. Each value was normalized with that of RNA Binding Family Member (PUM1) and set by the maximum value of control group. 
Table 2. List of primer sequence

\begin{tabular}{|c|c|c|c|}
\hline Gene Name & Accession Number & & Primer Sequence \\
\hline \multirow{2}{*}{ PUM1 } & \multirow{2}{*}{ NM_014676 } & hPum1-F & 5'-CGGTCGTCCTGAGGATAAAA-3' \\
\hline & & hPum1-R & 5'-CGTACGTGAGGCGTGAGTAA-3' \\
\hline \multirow{2}{*}{$B M A L 1$} & \multirow{2}{*}{ NM_001668 } & hBmal1-F & $5^{\prime}$-TTAAGAGGTGCCACCAATCC-3' \\
\hline & & hBmal1-R & 5'-CTTCCCTCGGTCACATCCTA-3' \\
\hline \multirow{2}{*}{ PER1 } & \multirow{2}{*}{ NM_002616 } & hPer1-F & 5'-GGACACTCCTGCGACCAG-3' \\
\hline & & hPer1-R & 5'-GGGAGTGAGGTGGAAGATCTAA-3' \\
\hline \multirow{2}{*}{ PER2 } & \multirow{2}{*}{ NM_022817.2 } & hPer2-F & $5^{\prime}$-TTCCCAGCAAACGTCCCAG-3' \\
\hline & & hPer2-R & 5'-GGTGCGTACCTACTCCCGT-3' \\
\hline \multirow{2}{*}{ PER3 } & \multirow{2}{*}{ NM_016831 } & hPer3-F & 5'-GCGCATTCTCATGACATACC-3' \\
\hline & & hPer3-R & 5'-TGCTGCTGCCTCATACTTTC-3' \\
\hline \multirow{2}{*}{$c-F O S$} & \multirow{2}{*}{ NM_005252.3 } & hc-Fos-F & 5'-CTACCACTCACCCGCAGACT-3' \\
\hline & & hc-Fos-R & 5'-AGGTCCGTGCAGAAGTCCT-3' \\
\hline \multirow{2}{*}{ c-JUN } & \multirow{2}{*}{ NM_002228.3 } & hc-Jun-F & 5'-CCAAAGGATAGTGCGATGTTT-3' \\
\hline & & hc-Jun-R & 5'-CTGTCCСТCTCCACTGCAAC-3' \\
\hline$M M P-1$ & NM_002421.3 & & Qiagen (PPH00120B) \\
\hline
\end{tabular}

\subsection{MMP1 Protein Determination by ELISA}

Pro MMP-1 protein levels in cell culture supernatants were quantified by ELISA (Human Pro MMP-1; DMP100; R\&D Systems, Minneapolis, MN, USA) according to the manufacturer's instructions.

\subsection{Establishment of a Stable Cell Line for Per2/Bmal1 Promoter-Based Reporter Gene Assay}

Each plasmid pGL4.15 expressing a firefly luciferase (LUC) purchased from Promega (\# 9PIE670, Madison, WI, USA) under the control of a 526bp PER2 promoter fragment from mouse genome and plasmid pGL4.27 expressing LUC purchased from Promega (\# 9PIE845, Madison, WI, USA) under the control of a 1.34-Kb BMAL1 promoter fragment from human genome was stably integrated into HaCaT keratinocytes. After hygromycin selection $(0.2 \mu \mathrm{g} / \mathrm{mL}$; Sigma, Ronkonkoma, NY, USA), one colony was cultured into 24-well cell culture plates and sub-cultured sequentially into 12-well and 6-well plates for five weeks for hygromycin selection. After hygromycin selection, single-cell-derived sub-clones were analyzed in bioluminescence monitoring over five days following treatment with $1 \mu \mathrm{M}$ dexamethasone for synchronization. Consequently, Per2pro-LUC / Bmal1pro-LUC stable cell line expressing PER2 / BMAL1 promoter and firefly luciferase gene was obtained.

\subsection{Bioluminescence Recording}

For live-cell bioluminescence monitoring, HaCaT reporter cell line was seeded to white 96-well plates (655083, Griner Bio One, Monroe, CA, USA) at density of $1.4 \times 104$ cells/well. After two days, cells were synchronized with $1 \mu \mathrm{M}$ dexamethasone (D1756, Sigma Aldrich, St. Louis, MO, USA) for one hour. The medium was then changed to a recording media: DMEM containing $1 \%$ fetal calf serum, 1\% penicillin/streptomycin, $10 \mathrm{mM}$ HEPES, pH 7.4, $0.2 \mathrm{mg} / \mathrm{mL}$ Hygromycin, and $1 \mathrm{mM}$ luciferin. Bioluminescence recordings were taken every hour for five days using Infinite M200 (Tecan, Männedorf, Switzerland). Raw data were de-trended by dividing data points by 24-h running average. Relative luminescence intensities from data were imported into Biological Rhythms Analysis Software System (BRASS, provided by Andrew Millar lab). Periods and relative amplitude error (RAE) were analyzed using FFT-NLLS suite. 


\subsection{Extraction of L. capitata}

Lespedeza capitata was purchased from Jeju Island, South Korea. The raw extract desiccated by using hot air drier at $50{ }^{\circ} \mathrm{C}$ overnight was grinded. Dried and pulverized aerial parts of L. capitata $(1 \mathrm{~kg})$ were extracted with $70 \%$ ethanol $(20 \mathrm{~kg})$ at $80^{\circ} \mathrm{C}$ for $3 \mathrm{~h}$. L. capitata extract (LCE) was filtered through $5-\mu \mathrm{m}$ charcoal filter and concentrated by evaporation. Concentrate was dried using a freeze dryer and powdered

\subsection{Pharmacological Treatment for Bioluminescence Recording}

To determine the effect of LCE on skin circadian rhythm, Per2pro-LUC cells were seeded into white 96-well plates (655083, Griner Bio One, Monroe, CA, USA) at density of $1.4 \times 104$ cells /well. After two days, cells were washed with PBS and treated with LCE (10, 25, and $50 \mu \mathrm{g} / \mathrm{mL})$ for $24 \mathrm{~h}$. Cells were then washed with PBS and replaced with freshly made recording medium. Bioluminescence was taken every hour for five days.

\subsection{Determination of Cell Number}

To determine cell number, cells were washed with PBS and dissociated by trypsin. Cells were then resuspended with DMEM containing 10\% FBS and cell number was measured using a cell counter (Millipore, Billerica, MA, USA). Cell number counted by a Scepter cell counter was based on Coulter principle of impedance-based particle detection [54]. Cells ranging in diameter between 10 to $22 \mu \mathrm{m}$ were counted as surviving cells [55].

\subsection{Statistical Analysis}

Data are presented as mean \pm SEM from three replicate measurements. Continuous variables were tested for normal distribution by using the Shapiro-Wilk test and for homogeneity of variance test by using Levene test. All data showed normal distribution. Two-tail unpaired $t$-test and one-way ANOVA followed by Bonferroni or Dunnett T3 post hoc depending on homogeneity of variance were used as appropriate for statistical differences. All calculations were carried out by using SPSS statistics.

Acknowledgments: This study was supported by a grant (R0002895) funded by the Ministry of Trade, Industry and Energy, Korea.

Author Contributions: Miji Yeom and Eunsun Jung conceived and designed the experiments. Miji Yeom and HansongI Lee performed the experiments. Miji Yeom, Eunsun Jung, Seoungwoo Shin, and Deokhoon Park analyzed and interpreted the data. Miji Yeom wrote the paper and Eunsun Jung corrected the paper. All authors read the manuscript and approved the final manuscript.

Conflicts of Interest: The authors have no conflict of interest related to this study to disclose.

\section{References}

1. Bunger, M.K.; Wilsbacher, L.D.; Moran, S.M.; Clendenin, C.; Radcliffe, L.A.; Hogenesch, J.B.; Simon, M.C.; Takahashi, J.S.; Bradfield, C.A. Mop3 is an essential component of the master circadian pacemaker in mammals. Cell 2000, 103, 1009-1017. [CrossRef]

2. Spoelstra, K.; Wikelski, M.; Daan, S.; Loudon, A.S.I.; Hau, M. Natural selection against a circadian clock gene mutation in mice. Proc. Natl. Acad. Sci. USA 2016, 113, 686-691. [CrossRef] [PubMed]

3. Kalsbeek, A.; van Heerikhuize, J.J.; Wortel, J.; Buijs, R.M. A diurnal rhythm of stimulatory input to the hypothalamo-pituitary-adrenal system as revealed by timed intrahypothalamic administration of the vasopressin V1 antagonist. J. Neurosci. 1996, 16, 5555-5565. [PubMed]

4. Ohdo, S.; Koyanagi, S.; Matsunaga, N.; Hamdan, A. Molecular basis of chronopharmaceutics. J. Pharm. Sci. 2011, 100, 3560-3576. [CrossRef] [PubMed]

5. Balsalobre, A.; Marcacci, L.; Schibler, U. Multiple signaling pathways elicit circadian gene expression in cultured Rat-1 fibroblasts. Curr. Biol. CB 2000, 10, 1291-1294. [CrossRef]

6. Pevet, P.; Challet, E. Melatonin: both master clock output and internal time-giver in the circadian clocks network. J. Physiol. Paris 2011, 105, 170-182. [CrossRef] [PubMed] 
7. Lamia, K.A.; Storch, K.-F.; Weitz, C.J. Physiological significance of a peripheral tissue circadian clock. Proc. Natl. Acad. Sci. USA 2008, 105, 15172-15177. [CrossRef] [PubMed]

8. Schibler, U. Circadian time keeping: the daily ups and downs of genes, cells, and organisms. Prog. Brain Res. 2006, 153, 271-282. [PubMed]

9. Brown, W.R. A review and mathematical analysis of circadian rhythms in cell proliferation in mouse, rat, and human epidermis. J. Investig. Dermatol. 1991, 97, 273-280. [CrossRef] [PubMed]

10. Henry, F.; Arrese, J.E.; Claessens, N.; Piérard-Franchimont, C.; Piérard, G.E. [Skin and its daily chronobiological clock]. Rev. Med. Liege 2002, 57, 661-665. [PubMed]

11. Denda, M.; Tsuchiya, T. Barrier recovery rate varies time-dependently in human skin. Br. J. Dermatol. 2000, 142, 881-884. [CrossRef] [PubMed]

12. Le Fur, I.; Reinberg, A.; Lopez, S.; Morizot, F.; Mechkouri, M.; Tschachler, E. Analysis of circadian and ultradian rhythms of skin surface properties of face and forearm of healthy women. J. Investig. Dermatol. 2001, 117, 718-724. [CrossRef] [PubMed]

13. Yosipovitch, G.; Xiong, G.L.; Haus, E.; Sackett-Lundeen, L.; Ashkenazi, I.; Maibach, H.I. Time-dependent variations of the skin barrier function in humans: transepidermal water loss, stratum corneum hydration, skin surface $\mathrm{pH}$, and skin temperature. J. Investig. Dermatol. 1998, 110, 20-23. [CrossRef] [PubMed]

14. Yosipovitch, G.; Sackett-Lundeen, L.; Goon, A.; Yiong Huak, C.; Leok Goh, C.; Haus, E. Circadian and ultradian ( $12 \mathrm{~h}$ ) variations of skin blood flow and barrier function in non-irritated and irritated skin-effect of topical corticosteroids. J. Investig. Dermatol. 2004, 122, 824-829. [CrossRef] [PubMed]

15. Sandu, C.; Dumas, M.; Malan, A.; Sambakhe, D.; Marteau, C.; Nizard, C.; Schnebert, S.; Perrier, E.; Challet, E.; Pévet, P.; et al. Human skin keratinocytes, melanocytes, and fibroblasts contain distinct circadian clock machineries. Cell. Mol. Life Sci. CMLS 2012, 69, 3329-3339. [CrossRef] [PubMed]

16. Grundschober, C.; Delaunay, F.; Pühlhofer, A.; Triqueneaux, G.; Laudet, V.; Bartfai, T.; Nef, P. Circadian regulation of diverse gene products revealed by mRNA expression profiling of synchronized fibroblasts. J. Biol. Chem. 2001, 276, 46751-46758. [CrossRef] [PubMed]

17. Janich, P.; Toufighi, K.; Solanas, G.; Luis, N.M.; Minkwitz, S.; Serrano, L.; Lehner, B.; Benitah, S.A. Human epidermal stem cell function is regulated by circadian oscillations. Cell Stem Cell 2013, 13, 745-753. [CrossRef] [PubMed]

18. Steinbrenner, H.; Ramos, M.C.; Stuhlmann, D.; Sies, H.; Brenneisen, P. UVA-mediated downregulation of MMP-2 and MMP-9 in human epidermal keratinocytes. Biochem. Biophys. Res. Commun. 2003, 308, 486-491. [CrossRef]

19. Vicentini, F.T.M.C.; He, T.; Shao, Y.; Fonseca, M.J.V.; Verri, W.A.; Fisher, G.J.; Xu, Y. Quercetin inhibits UV irradiation-induced inflammatory cytokine production in primary human keratinocytes by suppressing NF-кB pathway. J. Dermatol. Sci. 2011, 61, 162-168. [CrossRef] [PubMed]

20. Gaddameedhi, S.; Selby, C.P.; Kaufmann, W.K.; Smart, R.C.; Sancar, A. Control of skin cancer by the circadian rhythm. Proc. Natl. Acad. Sci. USA 2011, 108, 18790-18795. [CrossRef] [PubMed]

21. Kang, T.-H.; Reardon, J.T.; Kemp, M.; Sancar, A. Circadian oscillation of nucleotide excision repair in mammalian brain. Proc. Natl. Acad. Sci. USA 2009, 106, 2864-2867. [CrossRef] [PubMed]

22. Kang, T.-H.; Reardon, J.T.; Sancar, A. Regulation of nucleotide excision repair activity by transcriptional and post-transcriptional control of the XPA protein. Nucleic Acids Res. 2011, 39, 3176-3187. [CrossRef] [PubMed]

23. Nelson, A.R.; Fingleton, B.; Rothenberg, M.L.; Matrisian, L.M. Matrix metalloproteinases: biologic activity and clinical implications. J. Clin. Oncol. 2000, 18, 1135-1149. [CrossRef] [PubMed]

24. Quan, T.; Qin, Z.; Xia, W.; Shao, Y.; Voorhees, J.J.; Fisher, G.J. Matrix-degrading Metalloproteinases in Photoaging. J. Investig. Dermatol. Symp. Proc. 2009, 14, 20-24. [CrossRef] [PubMed]

25. Kim, J.; Lee, C.-W.; Kim, E.K.; Lee, S.-J.; Park, N.-H.; Kim, H.-S.; Kim, H.-K.; Char, K.; Jang, Y.P.; Kim, J.-W. Inhibition effect of Gynura procumbens extract on UV-B-induced matrix-metalloproteinase expression in human dermal fibroblasts. J. Ethnopharmacol. 2011, 137, 427-433. [CrossRef] [PubMed]

26. Westermarck, J.; Li, S.; Jaakkola, P.; Kallunki, T.; Grénman, R.; Kähäri, V.-M. Activation of Fibroblast Collagenase-1 Expression by Tumor Cells of Squamous Cell Carcinomas Is Mediated by p38 Mitogen-activated Protein Kinase and c-Jun NH2-terminal Kinase-2. Cancer Res. 2000, 60, 7156-7162. [PubMed] 
27. Fagot, D.; Asselineau, D.; Bernerd, F. Direct role of human dermal fibroblasts and indirect participation of epidermal keratinocytes in MMP-1 production after UV-B irradiation. Arch. Dermatol. Res. 2002, 293, 576-583. [CrossRef] [PubMed]

28. Fisher, G.J.; Kang, S.; Varani, J.; Bata-Csorgo, Z.; Wan, Y.; Datta, S.; Voorhees, J.J. Mechanisms of photoaging and chronological skin aging. Arch. Dermatol. 2002, 138, 1462-1470. [CrossRef] [PubMed]

29. Park, C.-H.; Moon, Y.; Shin, C.M.; Chung, J.H. Cyclic AMP suppresses matrix metalloproteinase-1 expression through inhibition of MAPK and GSK-3beta. J. Investig. Dermatol. 2010, 130, 2049-2056. [CrossRef] [PubMed]

30. Lee, B.; Li, A.; Hansen, K.F.; Cao, R.; Yoon, J.H.; Obrietan, K. CREB influences timing and entrainment of the SCN circadian clock. J. Biol. Rhythms 2010, 25, 410-420. [CrossRef] [PubMed]

31. Koyanagi, S.; Hamdan, A.M.; Horiguchi, M.; Kusunose, N.; Okamoto, A.; Matsunaga, N.; Ohdo, S. cAMP-response element (CRE)-mediated transcription by activating transcription factor-4 (ATF4) is essential for circadian expression of the Period2 gene. J. Biol. Chem. 2011, 286, 32416-32423. [CrossRef] [PubMed]

32. Obrietan, K.; Impey, S.; Smith, D.; Athos, J.; Storm, D.R. Circadian regulation of cAMP response element-mediated gene expression in the suprachiasmatic nuclei. J. Biol. Chem. 1999, 274, 17748-17756. [CrossRef] [PubMed]

33. Tischkau, S.A.; Mitchell, J.W.; Tyan, S.-H.; Buchanan, G.F.; Gillette, M.U. Ca2+/cAMP response element-binding protein (CREB)-dependent activation of Per1 is required for light-induced signaling in the suprachiasmatic nucleus circadian clock. J. Biol. Chem. 2003, 278, 718-723. [CrossRef] [PubMed]

34. Schmitt, J.M.; Stork, P.J.S. PKA phosphorylation of Src mediates cAMP's inhibition of cell growth via Rap1. Mol. Cell 2002, 9, 85-94. [CrossRef]

35. Mayr, B.M.; Canettieri, G.; Montminy, M.R. Distinct effects of cAMP and mitogenic signals on CREB-binding protein recruitment impart specificity to target gene activation via CREB. Proc. Natl. Acad. Sci. USA 2001, 98, 10936-10941. [CrossRef] [PubMed]

36. Houslay, M.D.; Kolch, W. Cell-type specific integration of cross-talk between extracellular signal-regulated kinase and cAMP signaling. Mol. Pharmacol. 2000, 58, 659-668. [CrossRef] [PubMed]

37. Okabe, T.; Kumagai, M.; Nakajima, Y.; Shirotake, S.; Kodaira, K.; Oyama, M.; Ueno, M.; Ikeda, M. The impact of HIF1 $\alpha$ on the Per2 circadian rhythm in renal cancer cell lines. PLoS ONE 2014, 9, e109693. [CrossRef] [PubMed]

38. Kondratov, R.V.; Kondratova, A.A.; Gorbacheva, V.Y.; Vykhovanets, O.V.; Antoch, M.P. Early aging and age-related pathologies in mice deficient in BMAL1, the core componentof the circadian clock. Genes Dev. 2006, 20, 1868-1873. [CrossRef] [PubMed]

39. Matsunaga, N.; Itcho, K.; Hamamura, K.; Ikeda, E.; Ikeyama, H.; Furuichi, Y.; Watanabe, M.; Koyanagi, S.; Ohdo, S. 24-hour rhythm of aquaporin-3 function in the epidermis is regulated by molecular clocks. J. Investig. Dermatol. 2014, 134, 1636-1644. [CrossRef] [PubMed]

40. Park, S.; Kim, K.; Bae, I.-H.; Lee, S.H.; Jung, J.; Lee, T.R.; Cho, E.-G. TIMP3 is a CLOCK-dependent diurnal gene that inhibits the expression of UVB-induced inflammatory cytokines in human keratinocytes. FASEB J. 2017, 32, 1510-1523. [CrossRef] [PubMed]

41. Kowalska, E.; Ripperger, J.A.; Hoegger, D.C.; Bruegger, P.; Buch, T.; Birchler, T.; Mueller, A.; Albrecht, U.; Contaldo, C.; Brown, S.A. NONO couples the circadian clock to the cell cycle. Proc. Natl. Acad. Sci. USA 2013, 110, 1592-1599. [CrossRef] [PubMed]

42. Kalfalah, F.; Janke, L.; Schiavi, A.; Tigges, J.; Ix, A.; Ventura, N.; Boege, F.; Reinke, H. Crosstalk of clock gene expression and autophagy in aging. Aging 2016, 8, 1876-1895. [CrossRef] [PubMed]

43. Li, H.-X.; Fu, X.-J.; Yang, K.; Chen, D.; Tang, H.; Zhao, Q.; Li, H.-X.; Fu, X.-J.; Yang, K.; Chen, D.; et al. The clock gene PER1 suppresses expression of tumor-related genes in human oral squamous cell carcinoma. Oncotarget 2016, 7, 20574-20583. [CrossRef] [PubMed]

44. Climent, J.; Perez-Losada, J.; Quigley, D.A.; Kim, I.-J.; Delrosario, R.; Jen, K.-Y.; Bosch, A.; Lluch, A.; Mao, J.-H.; Balmain, A. Deletion of the PER3 Gene on Chromosome 1p36 in Recurrent ER-Positive Breast Cancer. J. Clin. Oncol. 2010, 28, 3770-3778. [CrossRef] [PubMed]

45. Relógio, A.; Thomas, P.; Medina-Pérez, P.; Reischl, S.; Bervoets, S.; Gloc, E.; Riemer, P.; Mang-Fatehi, S.; Maier, B.; Schäfer, R.; et al. Ras-Mediated Deregulation of the Circadian Clock in Cancer. PLoS Genet. 2014, 10. [CrossRef] [PubMed] 
46. Guo, B.; Yang, N.; Borysiewicz, E.; Dudek, M.; Williams, J.L.; Li, J.; Maywood, E.S.; Adamson, A.; Hastings, M.H.; Bateman, J.F.; et al. Catabolic cytokines disrupt the circadian clock and the expression of clock-controlled genes in cartilage via an NFKB-dependent pathway. Osteoarthr. Cartil. 2015, 23, 1981-1988. [CrossRef] [PubMed]

47. Kawara, S.; Mydlarski, R.; Shivji, G.; Tavadia, S.K.; Suzuki, H.; Mamelak, A.J.; Freed, I.; Wang, B.; Watanabe, H.; Bjarnason, G.A.; et al. Low-dose Ultraviolet B Rays Alter the mRNA Expression of the Circadian Clock Genes in Cultured Human Keratinocytes. J. Investig. Dermatol. 2002, 119, 1220-1223. [CrossRef] [PubMed]

48. Pagani, L.; Schmitt, K.; Meier, F.; Izakovic, J.; Roemer, K.; Viola, A.; Cajochen, C.; Wirz-Justice, A.; Brown, S.A.; Eckert, A. Serum factors in older individuals change cellular clock properties. Proc. Natl. Acad. Sci. USA 2011, 108, 7218-7223. [CrossRef] [PubMed]

49. Antoch, M.P.; Kondratov, R.V. Pharmacological modulators of the circadian clock as potential therapeutic drugs: focus on genotoxic/anticancer therapy. Handb. Exp. Pharmacol. 2013, 217, 289-309.

50. Banerjee, S.; Wang, Y.; Solt, L.A.; Griffett, K.; Kazantzis, M.; Amador, A.; El-Gendy, B.M.; Huitron-Resendiz, S.; Roberts, A.J.; Shin, Y.; et al. Pharmacological Targeting of the Mammalian Clock Regulates Sleep Architecture and Emotional Behavior. Nat. Commun. 2014, 5, 5759. [CrossRef] [PubMed]

51. Cunningham, P.S.; Ahern, S.A.; Smith, L.C.; da Silva Santos, C.S.; Wager, T.T.; Bechtold, D.A. Targeting of the circadian clock via CK1 $/ \varepsilon$ to improve glucose homeostasis in obesity. Sci. Rep. 2016, 6. [CrossRef] [PubMed]

52. Shinozaki, A.; Misawa, K.; Ikeda, Y.; Haraguchi, A.; Kamagata, M.; Tahara, Y.; Shibata, S. Potent Effects of Flavonoid Nobiletin on Amplitude, Period, and Phase of the Circadian Clock Rhythm in PER2::LUCIFERASE Mouse Embryonic Fibroblasts. PLoS ONE 2017, 12. [CrossRef] [PubMed]

53. Spörl, F.; Schellenberg, K.; Blatt, T.; Wenck, H.; Wittern, K.-P.; Schrader, A.; Kramer, A. A Circadian Clock in HaCaT Keratinocytes. J. Investig. Dermatol. 2011, 131, 338-348. [CrossRef] [PubMed]

54. Ongena, K.; Das, C.; Smith, J.L.; Gil, S.; Johnston, G. Determining cell number during cell culture using the Scepter cell counter. J. Vis. Exp. 2010. [CrossRef] [PubMed]

55. Tai, C.-J.; Wang, W.-C.; Wang, C.-K.; Wu, C.-H.; Yang, M.-D.; Chang, Y.-J.; Jian, J.-Y.; Tai, C.-J. Fermented Wheat Germ Extract Induced Cell Death and Enhanced Cytotoxicity of Cisplatin and 5-Fluorouracil on Human Hepatocellular Carcinoma Cells. Evid.-Based Complement. Altern. Med. ECAM 2013, 2013. [CrossRef] [PubMed]

Sample Availability: Samples of the compounds Lespedeza capitate extract are available from the authors.

(C) 2018 by the authors. Licensee MDPI, Basel, Switzerland. This article is an open access article distributed under the terms and conditions of the Creative Commons Attribution (CC BY) license (http:/ / creativecommons.org/licenses/by/4.0/). 